
\title{
25 Research Suare \\ Anticoagulant in Patients with Pulmonary Embolism and Fatty Liver: A Case Report
}

\section{Sha-Sha Li}

Jinan University https://orcid.org/0000-0003-4346-7535

\section{Wei-Xian Lin}

Southern Medical University Nanfang Hospital

\section{Kun-Yu Huang}

Jinan University First Affiliated Hospital

\section{Sheng-Yang Chen}

The Third Affiliated Hospital of Shenzhen University: Shenzhen Luohu Hospital Group Luohu People's Hospital

\section{Juan Chen}

Southern Medical University Nanfang Hospital

\section{Yu-Ping Wang}

Jinan University First Affiliated Hospital

\section{Lian-Fang Xue}

Jinan University First Affiliated Hospital

Hui Liu

Jinan University First Affiliated Hospital

\section{Jing-Hao Wang}

Jinan University First Affiliated Hospital

Qing Zhang ( $\nabla$ zq1699@126.com )

Southern Medical University Nanfang Hospital

\section{Case report}

Keywords: Pulmonary embolism, Fatty liver, Bleeding risk, Thrombotic risk, Anticoagulant drugs, NOAC

Posted Date: September 28th, 2020

DOI: https://doi.org/10.21203/rs.3.rs-80036/v1

License: (c) (i) This work is licensed under a Creative Commons Attribution 4.0 International License. Read Full License 


\section{Abstract}

AIMS: Patients with liver disease are more prone to thrombosis and bleeding events than healthy people. The decision to use anticoagulation in patients with pulmonary embolism and liver disease requires a cautious evaluation of the risks of bleeding and the benefits of anticoagulation. In order to make a recommendation for patient with fatty liver that developed pulmonary embolism, we reported this case.

METHODS: In this paper, we reported a case of a patient with fatty liver that developed pulmonary embolism. The low molecular weight heparin sodium injection and different anticoagulants were evaluated for this patient.

RESULTS: After evaluating the efficacy and safety of different anticoagulants in patients with pulmonary embolism and liver dysfunction, rivaroxaban is more suitable for this patient to be treated by sequential therapy. After three weeks of treatment with rivaroxaban, the patient's blood routine test results were normal, and no side effect was found.

CONCLUSIONS: For patients with pulmonary embolism and fatty liver, maybe NOAC is more suitable.

\section{What Is Already Known About This Subject}

\section{WHAT IS ALREADY KNOWN ABOUT THIS SUBJECT}

Patients with liver disease are more prone to thrombosis and bleeding events than healthy people.

The decision to use anticoagulation in patients with pulmonary embolism and liver disease requires a cautious evaluation of the risks of bleeding and the benefits of anticoagulation.

\section{WHAT THIS STUDY ADDS}

After evaluating the efficacy and safety of different anticoagulants in patients with pulmonary embolism and liver dysfunction, rivaroxaban is more suitable for this patient to be treated by sequential therapy.

This case makes a anticoagulants recommendation for patient with fatty liver that developed pulmonary embolism.

As far as we know, this is the first reported anticoagulant therapy case for patients with pulmonary embolism and fatty liver.

\section{Introduction}

As the third most frequent cardiovascular disease, venous thromboembolism (VTE) can be divided into two types, i.e., deep vein thrombosis (DVT) and pulmonary embolism (PE). There are 100 to 200 cases of VTE per 100,000 people per year [1-3]. Although VTE can cause death in the acute phase or result in chronic illness and disability, it can usually be prevented. PE to the phenomenon of a substance in the 
bloodstream blocking the lung aorta or its branches, and the most common cause is DVT. Acute PE is the most serious clinical manifestation of VTE because it can be asymptomatic or discovered by chance, and in some situation, the initial manifestation of PE may even be sudden death. Thus PE is responsible for death, disability, and hospitalization of a large portion of patients [4, 5].

Anticoagulation is a recommended treatment for the patients with acute PE to prevent early death and recurrent symptoms of lethal VTE. For these patients, the standard treatment is a superposition of unfractionated heparin (UFH) with low molecular weight heparin (LMWH) or fondaparinux followed by a vitamin $\mathrm{K}$ antagonist (VKA) or a direct and reversible inhibitor of factor Xa (rivaroxaban, apixaban, dabigatran or edoxaban) is the standard treatment [1]. The common adverse reactions of these anticoagulant drugs are drug-induced liver injury and bleeding.

Due to that liver is the primary site to synthesize most of the coagulation factors and fibrin which are related to the coagulation process, it is logical that liver dysfunction may be related to the disorders of coagulation process and that the coagulation abnormalities become more pronounced as the liver disease progresses. Since liver can synthesize coagulation factors, including factors $\mathrm{V}, \mathrm{VII}, \mathrm{IX}, \mathrm{X}$, and $\mathrm{Xi}$ ), and anticoagulation factors such as proteins, protein C, antithrombin (AT), fibrinolytic factors, etc., hemorrhage or thrombosis may occur in liver disease [6]. Furthermore, the level of vitamin $\mathrm{K}$ in patients

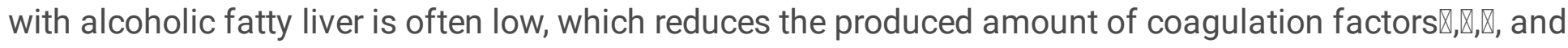

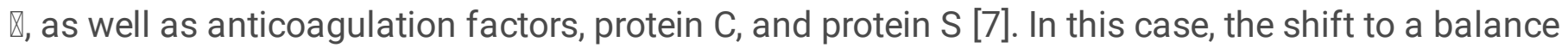
between hemorrhage and thrombosis is a difficult point in clinical treatment. For patients with pulmonary embolism and fatty liver, how to rationally select anticoagulants is indeed a challenge for clinical pharmacists and doctors. This study reported a case of a patient with pulmonary embolism and fatty liver requiring anticoagulant therapy.

\section{Case Report}

A 31-year-old man weighing $70 \mathrm{~kg}$ with a history of fatty liver was sent to our emergency department due to chest pain and dyspnea for 7 days and fever for 4 days. His highest temperature was $40{ }^{\circ} \mathrm{C}$ and he occasionally coughed without expectoration or hemoptysis. His d-dimer was $0.77 \mathrm{mg} / \mathrm{L}$, alanine aminotransferase (ALT) was $98 \mathrm{U} / \mathrm{L}$, aspartate aminotransferase (AST) was $60 \mathrm{U} / \mathrm{L}$, total bilirubin (TBIL) was $8.7 \mathrm{~mol} / \mathrm{L}$, and Albumin was $43.8 \mathrm{~g} / \mathrm{L}$. His prothrombin time (PT) was $13.4 \mathrm{~s}$, fibrinogen concentration was $5.00 \mathrm{~g} / \mathrm{L}$, and serum creatinine (CR) was $68 \mathrm{~mol} / \mathrm{L}$. The computer tomography pulmonary angiography (CTPA) showed the following results: 1 . There was a high possibility of embolization of multiple small branches of the left pulmonary artery. The heart shadow increased and the ventricular wall slightly thickened. 2. Both lungs were scattered with inflammation, centered at the left lower lobe. 3. A small amount of pleural effusion was observed on the left side, with inadequate expansion of adjacent lung tissues. Abdominal ultrasound showed 1) fatty and large liver, 2) less smooth gallbladder wall, and 3) no obvious abnormalities in spleen and pancreas. He was subsequently admitted to our hospital and started anticoagulant therapy with $0.6 \mathrm{~mL}$ low molecular weight sodium heparin injection, given subcutaneously every $12 \mathrm{~h}$. Epistaxis and hematuria (Red $78.8 / \mu \mathrm{L}$ ) were present on the 
second day of admission. We determined it was a side effect of LMWH. Then we reduced the dose of low molecular weight sodium heparin injection to $0.4 \mathrm{ml}$, given subcutaneously every $12 \mathrm{~h}$. After reducing the dose, the patient did not have obvious symptoms such as epistaxis and hematuria any more. His D-dimer was $11.16 \mathrm{mg} / \mathrm{L}$, ALT was $317 \mathrm{U} / \mathrm{L}$, AST was $177 \mathrm{U} / \mathrm{L}$, DBIL was $23.7 \mu \mathrm{mol} / \mathrm{L}$, TBIL was $33.4 \mu \mathrm{mol} / \mathrm{L}, \mathrm{PT}$ was $12.0 \mathrm{~s}$, PT-INR was 1.05, and Fbg C was $6.65 \mathrm{~g} / \mathrm{L}$. His high ALT and AST level may be due to the outof-hospital use of antipyretics. Both levels recovered after the administration of glutathione $(2 \mathrm{~g}$, once daily) and polyene phosphatidylcholine injection ( $10 \mathrm{ml}$, once daily) for three days. For his pneumonia, cefoperazone ( $2 \mathrm{~g}$, twice daily) was administrated for 7 days. On Day 10, due to the inconvenience of subcutaneous injection, LMWH was discontinued and replaced with Rivaroxaban $15 \mathrm{mg}$ administered orally twice daily. His ALT level was $73 \mathrm{U} / \mathrm{L}$, AST was $25 \mathrm{U} / \mathrm{L}$, D-dimer was $8.00 \mathrm{mg} / \mathrm{L}$, WBC was $7.23 \times$ $10^{9} / \mathrm{L}$, and NEU\% was $65.0 \%$. He was discharged from our hospital, continuing oral anticoagulants after discharge. After three weeks of rivaroxaban treatment, the patient's blood routine tests were normal, without any side effect.

\section{Discussions}

In healthy individuals, a balance between procoagulant and anti-haemostatic factors maintains proper haemostasis, thus avoiding abnormal bleeding or coagulation. Although this process involves in many types of cells and organs, the liver produces most of the proteins that regulate hemostasis [7]. The liver can synthesize coagulation factors, coagulation inhibitors, and fibrinolytic proteins and is therefore essential for hemostasis[6]. Hepatic dysfunction inhibits the synthesis of most coagulation factors. Furthermore, the malnourished patients with liver disease, especially the active drinkers have low levels of vitamin $\mathrm{K}$, which reduces the produced amount of procoagulation factors II, VII, IX, and X and anticoagulation factors, protein $\mathrm{C}$ and protein $\mathrm{S}$ [7]. In addition, thrombocytopenia (platelet counts < $150,000 / \mu \mathrm{L}$ ) is one of the mostly reported complications in patients with chronic liver disease. According to reports, up to $76 \%$ of cirrhotic patients have this complication [8] while fibrinolysis occurs in as many as $30 \%$ of cirrhotic patients [9]. Although the patient had a normal level of platelets, he had a history of epistaxis and was treated with nadroparin calcium ( $0.6 \mathrm{ml}$, twice a day). His routine urine test revealed hematuria (Red 78.8/ $\mu \mathrm{l})$. The clinical manifestation showed that this patient had an increased risk of bleeding. Besides, deep venous thrombosis (DVT) or pulmonary embolism (PE) has been reported to have an incidence of $0.5 \%-6.3 \%$ [6]. In addition, bacterial infections and chronic inflammation can affect the synthesis of these endogenous coagulation factors and change blood flow. The patient's blood pressure was stable and his hemodynamics was stable, too. However, this patient had a high infection index, which indicated a high coagulating state. The computer tomography pulmonary angiography (CTPA) showed he was at high risk of multiple small branches embolism of the left pulmonary artery. Although the patients with liver disease have a higher risk of bleeding, they may benefit from preventive or therapeutic anticoagulation. However, due to the lack of studies, it is challenging to make clinical decisions on the optimal dose, duration, monitoring, or selection of anticoagulant, and more importantly, to understand the clear clinical benefit and safety [6]. 
The effect of LMWH on thrombin generation (TG) in the patients with different phases of cirrhosis was evaluated in vitro. Mean antithrombin (AT) levels and the endogenous thrombin potential (ETP) ratio were evaluated in cirrhotic patients and healthy controls. Compared to control groups, the mean AT levels and ETP ratio in all cirrhotic groups were dramatically decreased (the 0.35 ETP ratios cirrhotic and control groups were $0.26 \pm 0.1$ and $0.48 \pm 0.1$, respectively, $P<0.001$ ). In addition, the decreasing trends of AT levels and ETP ratio were linearly correlated with the severity of liver disease. Complete TG inhibition by LMWH at $0.7 \mathrm{U}$ anti-Xa mL concentration was observed in 9 out of 30 patients with advanced cirrhosis (Child Pugh B and C), whereas complete TG inhibition was only observed in $1 / 10$ controls [10]. This study suggests that the patients with cirrhosis have increased response to LMWH anticoagulants. In addition, as the liver disease gets more severe, the response to LMWH anticoagulants is increased. Depending on the severity of liver disease, the dose of LMWH might need to be adjusted to prevent excessive anticoagulation and possible bleeding complications.

The Child-Turcotte-Pugh (CTP) grading system is widely used to evaluate liver function in patients with chronic liver diseases $[11,12]$. According to CTP system, this patient had a CTP rating of CTP A with a score of 5. Low molecular weight heparin sodium at the dose of $0.6 \mathrm{ml}$ (Fraxiparine) was injected subcutaneously every $12 \mathrm{~h}$. On the second day of admission, he presented epistaxis and hematuria (Red $78.8 / \mu \mathrm{L}$ ). Unfortunately, there was no study on dose adjustment in patients with different grades of CTP. According to clinical experience, we changed the dose of $\mathrm{LMWH}$ to $0.4 \mathrm{ml}$ with the subcutaneous administration every $12 \mathrm{~h}$. After the dose adjustment, the patient did not have obvious epistaxis and hematuria any more. Thus, for this patient, an adjusted dose of $0.4 \mathrm{ml} \mathrm{LMWH}$ was more suitable.

Oral anticoagulants should be started as soon as possible and preferably on the same day as the parenteral anticoagulant. Now, NOACs are commonly used for the prevention and treatment of multiple indications, including venous thromboembolism (VTE) and stroke prophylaxis in atrial fibrillation. In addition, the American College of Clinical Pharmacy guidelines have suggested using NOACs as first-line treatment for PE [13]. NOACs were compared to VKAs in a variety of conditions, and the results indicated that NOACs had equal or even better treatment efficacy for VTE than VKAs. In addition, according to the pooled data, NOACs caused fewer bleeding complications than VKAs. However, to date, the patients with liver disease have been excluded in all the reported prospective studies on NOACs. The incidences of thrombosis and bleeding events in patients with cirrhosis were higher than those in healthy individuals. The risks and benefits of using anticoagulation in patients with cirrhosis need to be carefully evaluated.

A meta-analysis with 152,116 patients in 29 RCT studies (with an average follow-up period of 16 months) evaluated drug-induced liver injury (DILI) by NOACs and conventional anticoagulants. The result showed that NOAC did not cause a higher risk of DILI (RR 0.90, 95\% $\mathrm{Cl} 0.72$ to $1.13,12=0 \%$ [12].

In a retrospective cohort study, therapeutic anticoagulation was administered to cirrhotic patients for more than 3 years to treat thrombosis or prevent stroke in patients with atrial fibrillation. During the study period, 27 cirrhotic patients (11 patients with CTPA, 12 patients with CTPB and 4 patients with CTPC) were treated with a NOAC (apixaban $5 \mathrm{mg}$ BID with or without a $10 \mathrm{mg}$ BID loading dose; rivaroxaban 
$15 \mathrm{mg}$ daily with or without a $20 \mathrm{mg}$ daily loading dose) and 18 patients (7 patients with CTPA, 9 patients with CTPB, and 2 patients with CTPC) were treated with VKA (warfarin dosed to an INR target of 2-3 or an INR 1 unit above baseline) or low molecular weight heparin (LMWH, $1 \mathrm{mg} / \mathrm{kg}$ BID or $1.5 \mathrm{mg} / \mathrm{kg}$ daily). Both patient groups with the treatment of NOAC and conventional anticoagulants had similar results in the total bleeding events ( 8 NOAC vs. 10 other, $p=0.12$ ). However, in the patient group with the treatment of NOAC, the major bleeding episodes were significantly fewer, (1(4\%) vs. $5(28 \%), p=0.03)$ [14], which might be due to the low dose of NOAC. A regular dose of NOAC may have similar safety as traditional anticoagulants in the treatment of cirrhosis. In another 3-year retrospective study, 39 patients with cirrhosis (CTP A and CTP B) were treated with anticoagulation therapy (20 patients treated by NOAC, apixaban $5 \mathrm{mg}$ twice daily or rivaroxaban $20 \mathrm{mg}$ daily, and 19 patients treated by traditional anticoagulation, LMWH $1 \mathrm{mg} / \mathrm{kg}$ twice daily or warfarin variable with INR). The treatment results of both patient groups were evaluated and compared. Compared to traditional anticoagulation, a regular dose of NOAC had similar safety characteristics in patients with cirrhosis [15].

Hepatic dysfunction affects not only the metabolism of oral anticoagulant, but also the coagulation function in moderate and severe patients. A study by Dagmar Kubitza reported that moderate (but not mild) liver insufficiency caused the reduction in systemic clearance of rivaroxaban after a single $10 \mathrm{mg}$ dose, resulting in the higher exposure and improved pharmacodynamic effects of rivaroxaban [16]. Another study by Jochen Graff reported that in subjects with moderate liver insufficiency (i.e. Child-Pugh classification B), the area under the plasma concentration-time curve (AUC) increased by 2.27 fold for rivaroxaban (10 mg single dose), 1.09 fold for apixaban (5 mg single dose), 4.8\% for edoxaban (15 mg single dose), and $5.6 \%$ for dabigatran (150 mg single dose) [17]. Specific marker limitations for impaired liver function for rivaroxaban, apixaban and dabigatran are according to both the Child-Pugh classification and liver-related exclusion criteria used in pivotal clinical trials.

Due to the therapeutic dose of $\mathrm{LMWH}$, this patient was at a higher risk of bleeding. There is a significant individual variation in the efficacy of warfarin; therefore, the dose should be individualized according to blood drug concentration monitoring. Perhaps apixaban is the best choice for this patient, but it is not yet available in China. Following the instructions, the patient was given rivaroxaban $15 \mathrm{mg}$, bid $20 \mathrm{mg}$ (three weeks prior), and qd (three weeks after). During the follow-up, he did not show symptoms such as bleeding from gums and gastrointestinal tract. After three weeks of the treatment with rivaroxaban, the patient's blood routine tests showed normal, without any side effects.

\section{Conclusions}

Patients with cirrhosis have a higher incidence of thrombosis and bleeding events than healthy individuals, and patients requiring anticoagulation therapy are at a high risk of bleeding. In the treatment of PE, NOACs were found not inferior to VKAs. In addition, according to the pooled data, NOACs caused a lower risk of bleeding than VKAs. Furthermore, NOACs are not significantly affected by food, thus it may be more suitable for patients with pulmonary embolism and fatty liver. 


\section{Declarations}

\section{Ethics approval and consent to participate}

Not applicable.

\section{Consent for publication}

The patient gave informed consent for this case report.

\section{Availability of data and materials}

The data in this paper was available.

\section{Competing interests and Funding}

The authors declare no competing financial interest. No potential conflict of interest exists with this research, and no study sponsor is involved.

\section{Authors' contributions}

Sha-Sha Li and Kun-Yu Huang wrote the paper. Jing-Hao Wang and Qing Zhang reviewed and edited the paper. Wei-Xian Lin is the Principal Investigator. Wei-Xian Lin and Juan Chen examined the patient and ruled out the patient. Sheng-Yang Chen and Lian-Fang Xue performed the CTPA reading. Yu-Ping Wang and Hui Liu performed the drug probability scale. All authors read and approved the final manuscript.

\section{Acknowledgements}

Not applicable.

\section{References}

1. Konstantinides SV, Torbicki A, Agnelli G, Danchin N, Fitzmaurice D, Galie N, Gibbs JS, Huisman MV, Humbert M, Kucher N, Lang I, Lankeit M, Lekakis J, Maack C, Mayer E, Meneveau N, Perrier A, Pruszczyk P, Rasmussen LH, Schindler TH, Svitil P, Vonk Noordegraaf A, Zamorano JL, Zompatori M. 2014 ESC guidelines on the diagnosis and management of acute pulmonary embolism. Eur Heart $\mathrm{J}$ 2014; 35: 3033-69, 69a-69k.

2. Menichetti M, Rosso S, Menegatti E, Pazzaglia M. Use of rivaroxaban in an elderly patient with intermediate-low early mortality risk due to pulmonary embolism: a case report. J Med Case Rep 2015; 9: 274.

3. Rivera-Lebron B, McDaniel M, Ahrar K, Alrifai A, Dudzinski DM, Fanola C, Blais D, Janicke D, Melamed R, Mohrien K, Rozycki E, Ross CB, Klein AJ, Rali P, Teman NR, Yarboro L, Ichinose E, Sharma AM, Bartos JA, Elder M, Keeling B, Palevsky H, Naydenov S, Sen P, Amoroso N, Rodriguez-Lopez JM, Davis GA, Rosovsky R, Rosenfield K, Kabrhel C, Horowitz J, Giri JS, Tapson V, Channick R. Diagnosis, 
Treatment and Follow Up of Acute Pulmonary Embolism: Consensus Practice from the PERT Consortium. Clin Appl Thromb Hemost 2019; 25: 1076029619853037.

4. Yirgin G, Ates I Fau - Katipoglu B, Katipoglu B Fau - Demir BF, Demir Bf Fau - Yilmaz N, Yilmaz N. Pulmonary embolism due to synthetic cannabinoid use: Case report. Turk Kardiyol Dern Ars 2018; 46: 411-13.

5. Pleticha J, Sutton EM. Intraoperative Pulmonary Embolism: A Case Report Emphasizing the Utility of Electrocardiogram. A A Case Rep 2017; 9: 349-52.

6. Marks PW. Hematologic manifestations of liver disease. Semin Hematol 2013; 50: 216-21.

7. Shah NL, Intagliata NM, Northup PG, Argo CK, Caldwell SH. Procoagulant therapeutics in liver disease: a critique and clinical rationale. Nat Rev Gastroenterol Hepatol 2014; 11: 675-82.

8. Afdhal N, McHutchison J, Brown R, Jacobson I, Manns M, Poordad F, Weksler B, Esteban R. Thrombocytopenia associated with chronic liver disease. J Hepatol 2008; 48: 1000-7.

9. Bennani-Baiti N, Daw HA. Primary hyperfibrinolysis in liver disease: a critical review. Clin Adv Hematol Oncol 2011; 9: 250-2.

10. Senzolo M, Rodriguez-Castro KI, Rossetto V, Radu C, Gavasso S, Carraro P, Zerbinati P, Sartori MT, Simioni P. Increased anticoagulant response to low-molecular-weight heparin in plasma from patients with advanced cirrhosis. J Thromb Haemost 2012; 10: 1823-9.

11. Pugh Rn Fau - Murray-Lyon IM, Murray-Lyon Im Fau - Dawson JL, Dawson JI Fau - Pietroni MC, Pietroni Mc Fau - Williams R, Williams R. Transection of the oesophagus for bleeding oesophageal varices. Br J Surg 1973; 60: 646-49.

12. Imura S, Shimada M, Utsunomiya T. Recent advances in estimating hepatic functional reserve in patients with chronic liver damage. Hepatol Res 2015; 45: 10-9.

13. Konstantinides Sv Fau - Meyer G, Meyer G Fau - Becattini C, Becattini C Fau - Bueno H, Bueno H Fau Geersing G-J, Geersing Gj Fau - Harjola V-P, Harjola Vp Fau - Huisman MV, Huisman Mv Fau Humbert M, Humbert M Fau - Jennings CS, Jennings Cs Fau - Jimenez D, Jimenez D Fau - Kucher N, Kucher N Fau - Lang IM, Lang Im Fau - Lankeit M, Lankeit M Fau - Lorusso R, Lorusso R Fau Mazzolai L, Mazzolai L Fau - Meneveau N, Meneveau N Fau - Ni Ainle F, Ni Ainle F Fau - Prandoni P, Prandoni P Fau - Pruszczyk P, Pruszczyk P Fau - Righini M, Righini M Fau - Torbicki A, Torbicki A Fau Van Belle E, Van Belle E Fau - Zamorano JL, Zamorano JL. 2019 ESC Guidelines for the diagnosis and management of acute pulmonary embolism developed in collaboration with the European Respiratory Society (ERS). Eur Heart J 2020; 41: 543-603.

14. Hum J, Shatzel JJ, Jou JH, Deloughery TG. The efficacy and safety of direct oral anticoagulants vs traditional anticoagulants in cirrhosis. Eur J Haematol 2017; 98: 393-97.

15. Intagliata NM, Henry ZH, Maitland H, Shah NL, Argo CK, Northup PG, Caldwell SH. Direct Oral Anticoagulants in Cirrhosis Patients Pose Similar Risks of Bleeding When Compared to Traditional Anticoagulation. Dig Dis Sci 2016; 61: 1721-27.

16. Kubitza D, Roth A Fau - Becka M, Becka M Fau - Alatrach A, Alatrach A Fau - Halabi A, Halabi A Fau Hinrichsen H, Hinrichsen H Fau - Mueck W, Mueck W. Effect of hepatic impairment on the 
pharmacokinetics and pharmacodynamics of a single dose of rivaroxaban, an oral, direct Factor Xa inhibitor. Br J Clin Pharmacol 2013; 76: 89-98.

17. Graff J, Harder S. Anticoagulant therapy with the oral direct factor Xa inhibitors rivaroxaban, apixaban and edoxaban and the thrombin inhibitor dabigatran etexilate in patients with hepatic impairment. Clin Pharmacokinet 2013; 52: 243-54. 